\title{
Características morfológicas e moleculares e acúmulo de proteína em grãos de variedades de arroz do Maranhão(1)
}

\author{
Elisangela Sousa de Araújo(2), Sonia Regina de $\operatorname{Souza}^{(3)}$ e Manlio Silvestre Fernandes ${ }^{(2)}$
}

\begin{abstract}
Resumo - O grão de arroz apresenta baixos teores de proteína, mas contém glutelina, uma proteína de melhor qualidade para a alimentação humana do que a de outros cereais. O objetivo deste trabalho foi caracterizar, por meio de descritores morfológicos e moleculares (RAPD), algumas variedades tradicionais de arroz do Estado do Maranhão que apresentam altos teores de proteínas nos grãos (mais de 10\%) e são tolerantes ao estresse nutricional e ao Al tóxico. As 33 variedades estudadas foram separadas em cinco grupos baseados nas características morfológicas e quatro grupos utilizando marcadores RAPD, que não coincidiram entre si. Teores elevados de proteína no grão estavam presentes aleatoriamente em todos os grupos. No entanto, verificou-se maior acúmulo de proteína em plantas cujas sementes tinham uma menor relação comprimento/largura de grão.
\end{abstract}

Termos para indexação: Oryza sativa, marcador genético, proteína bruta.

\section{Morphological and molecular traits and accumulation of grain protein in rice varieties from Maranhão, Brazil}

\begin{abstract}
Rice grain have low protein content but they present glutelin, a protein of higher nutritional quality than proteins of other cereal crops. The objective of this work was to characterize, by morphological and molecular markers, some land races from Maranhão State, Brazil, with high protein content (over 10\%) and tolerance to $\mathrm{Al}^{3+}$ and nutritional stress. The 33 varieties under study were fit in five groups based on morphology, and in four groups when RAPD markers were used. These two groupings are not coincident as far as grain protein content are concerned. High grain protein plants were found randomly all over the groups. However, highest proteins contents are associated with plants with the lowest length/width ratio.
\end{abstract}

Index terms: Oryza sativa, genetic markers, crude protein.

\section{Introdução}

A variabilidade encontrada nas plantas é a base do melhoramento genético para o desenvolvimento de cultivares tolerantes à baixa disponibilidade de nutrientes e à presença de elementos tóxicos (Glass et al., 1981), com maior eficiência no uso de $\mathrm{N}$ e potencial genético para maior acúmulo de proteína no grão (Molino, 1992).

Com o advento da tecnologia do DNA recombinante, novos métodos foram desenvolvidos,

\footnotetext{
(1) Aceito para publicação em 7 de julho de 2003.

(2) Universidade Federal Rural do Rio de Janeiro (UFRRJ),

Dep. de Solos-Nutrição de Plantas, BR 465, km 47 Antiga

Estrada Rio-São Paulo, CEP 23851-000 Seropédica, RJ.

E-mail: elis_sa@yahoo.com,manlio@ufrrj.br

(3) UFRRJ, Dep.de Química-Bioquímica.E-mail: soniabq@ufrrj.br
}

entre os quais se destacam os marcadores moleculares (marcadores de DNA). Trata-se de uma técnica cujo objetivo é fornecer um conhecimento do genoma das plantas, auxiliando nas decisões do melhoramento vegetal, tais como a incorporação de características desejadas em cultivares ou populações, em diferentes etapas do processo de melhoramento, utilizando-se meios clássicos de recombinação (Thomas et al., 1993; Ferreira \& Grattapaglia, 1998).

Marcadores moleculares são regiões do genoma passíveis de serem detectadas e cuja presença ou ausência pode caracterizar um organismo, porém, a seqüência e a função dos nucleotídeos, na maioria das vezes são desconhecidas (Gostimsky et al., 1999). Por isso, inúmeras técnicas têm sido usadas para a detecção de variabilidade genética ou polimorfismo genético em organismos, entre elas: isoenzimas, 
Polimorfismo no Comprimento de Fragmentos de Restrição (RFLP), microssatélites (SSR), Polimorfismo de Comprimentos de Fragmentos Amplificados (AFLP) e Polimorfismo de DNA Amplificado ao Acaso (RAPD) entre outras.

$\mathrm{O}$ arroz é um dos cereais que apresentam menor teor protéico, entretanto, seus grãos possuem uma proteína de melhor qualidade, a glutelina. Souza et al. (1993) observaram que o aumento do teor de proteína bruta em arroz é acompanhado por um aumento na fração glutelina, ou seja, aumentos no teor de proteína são acompanhados por aumentos na qualidade nutricional do grão.

No Estado do Maranhão, o arroz é produzido por pequenos agricultores, cujas propriedades rurais, cerca de $85 \%$, têm menos de 100 ha (Teixeira et al., 1991). Como nem todas as variedades de arroz produzidas no Estado têm boa produtividade, a introdução de variedades mais produtivas vem ocorrendo. A substituição do material local por variedades melhoradas, no entanto, representa ameaça à reserva genética (Fonseca et al., 1982).

O objetivo deste trabalho foi caracterizar variedades de arroz, do Maranhão, com altos teores de proteína nos grãos e tolerância ao estresse nutricional e ao Al tóxico, por meio de descritores morfológicos e moleculares (RAPD) e verificar seu relacionamento com o acúmulo de proteína no grão.

\section{Material e Métodos}

\section{Material genético}

Foram utilizadas 33 variedades de arroz (Oryza sativa L.) coletadas no campo, na safra de 2000 , junto aos agricultores da região da Baixada Maranhense, que as cultivam sob sistema de sequeiro.

A região da Baixada Maranhense está inserida em uma Área de Proteção Ambiental (APA) do Estado do Maranhão, e é caracterizada por apresentar período de estiagem (ou verão) e período de chuvas (ou inverno). Na época chuvosa, ocorre o extravasamento dos grandes rios e os campos sofrem inundações, permanecendo alagados em parte do ano.

O clima desta região oscila entre o equatorial e o subequatorial (Am e Aw, na classificação de Köppen), com temperatura média anual de $27^{\circ} \mathrm{C}$ e índice pluviométrico de 2.089,2 mm (Universidade Estadual do Maranhão, 1999).

\section{Características morfológicas}

As 33 variedades coletadas foram analisadas quanto às características morfológicas, de acordo com Fonseca et al. (1982) e com os descritores recomendados pelo Serviço Nacional de Proteção de Cultivares (SNPC). A caracterização morfológica foi realizada no Banco de Germoplasma (BAG) da Embrapa-Centro Nacional de Pesquisa de Arroz e Feijão, GO.

Foram avaliados os seguintes marcadores morfológicos qualitativos em amostras de aproximadamente $200 \mathrm{~g}$ de sementes: arista, cor das glumelas, pubescência das glumelas, tipo de grão (média de 20 grãos), forma do grão determinada pela razão comprimento/largura -, cor do apículo e peso de 1.000 grãos em amostras com quatro repetições.

\section{Marcadores RAPD}

$\mathrm{Na}$ análise molecular, sementes das 33 variedades de arroz coletadas foram fumigadas com sulfito de alumínio, esterilizadas em solução a 5\% de hipoclorito de sódio, lavadas e germinadas em placas de Petri contendo água destilada. Após a germinação, 20 plântulas de cada variedade foram transferidas para uma solução de $\mathrm{CaSO}_{4}$ 0,5 mM. Aproximadamente aos 15 dias, foram retiradas amostras de folhas de cada variedade para a extração de DNA em solução tampão CTAB (Ferreira \& Grattapaglia, 1998). A quantidade de DNA foi estimada pela razão de A260/ A280, em que cada unidade de absorvância correspondeu à concentração de $50 \mu \mathrm{L} / \mathrm{mL}$ de DNA de fita dupla (Sambrook et al., 1989).

Depois da extração e determinação da concentração do DNA, fez-se a otimização da técnica do RAPD, de acordo com Williams et al. (1990). A reação de amplificação ficou com volume final de $16 \mu \mathrm{L}$ contendo $1,6 \mu \mathrm{L}$ de Tampão $10 \mathrm{X}$ (Kit Promega), 2,3 mM $\mathrm{MgCl}_{2} ; 0,2 \mathrm{mM}$ de cada dNTP; $0,2 \mu \mathrm{M}$ do primer; $3 \mu \mathrm{g} / \mu \mathrm{L}$ de BSA; 1,0 unidade da Taq polimerase; $17 \mathrm{ng}$ de DNA molde, completando o volume final com água ultrapura. Para cada reação, houve uma testemunha, substituindo o DNA por água. Foram utilizados os iniciadores do kit A da Operon Technologies, com conteúdo GC de $60 \%$ a $70 \%$.

Os produtos de amplificação foram submetidos à eletroforese em gel de agarose 2,0\% em tampão TBE 0,5 X com voltagem de $100 \mathrm{~V}$ por duas horas. Após a corrida, o gel foi tratado com brometo de etídio $(0,2 \%)$ por 3 minutos, lavado em água destilada, e posteriormente visualizado em transiluminador UV e fotografado com câmera Polaroid. 


\section{Análise dos dados morfológicos e moleculares}

Os dados morfológicos e moleculares foram analisados como presença (1) e ausência (0) em função das bandas detectadas no gel, essa análise foi realizada por meio do software NTSYS (Rohlf, 2000; Dahlberg et al., 2002). A matriz de similaridade genética foi calculada utilizandose o índice de similaridade de Jaccard (1976). O dendrograma foi construído usando o algoritmo Unweighted Pair Groups Method with Arithmetic Mean (UPGMA) considerandose a matriz de similaridade (análise de agrupamento).

\section{Determinação do teor de proteína bruta dos grãos}

As amostras das 33 variedades de arroz coletadas na região da Baixada Maranhense foram compostas por 20 grãos descascados, nos quais se determinou o $\mathrm{N}$ total por digestão sulfúrica e destilação (Tedesco et al., 1998). Para se obter o teor de proteína bruta dos grãos, os valores de $\mathrm{N}$ total foram multiplicados por 5,95, fator baseado em $16,8 \%$ na glutelina, a principal proteína de reserva do arroz (Juliano, 1985).

\section{Resultados e Discussão}

\section{Descritores morfológicos}

Na coloração das glumas e glumelas, a cor predominante foi a palha (Tabela 1). Em relação ao apículo, houve maior variação, predominando a cor amarelopalha, sendo esta característica uma das que mais influenciou a diferenciação morfológica. A presença de arista foi comum nas variedades ovaladas. Houve uma predominância de grãos longos e semi-arredondados entre as variedades. O comprimento e a forma do grão são características herdadas independentemente e que podem apresentar diversas combinações (Silva, 1999).

O peso de 1.000 grãos variou de 18,00 a $34,12 \mathrm{~g}$, e as variedades Palha murcha (33) e Arroz 70 (12) apresentaram os maiores valores de comprimento e peso de grãos. Avaliando a diversidade genética com dez caracteres agronômicos em 72 variedades de arroz de várzea, Rangel et al. (1991) observaram que o maior responsável pelas diferenças nas variedades foi o peso de grãos. Resultados semelhantes foram obtidos em feijão por Sing et al. (1996) e Fonseca \& Silva (1999).
Dahlberg et al. (2002) classificaram 8.000 sementes de sorgo, fazendo distinção entre as variedades, e entre as variedades das espécies selvagens, utilizando apenas a análise morfológica das sementes. Segundo estes autores, a análise morfológica da semente é viável e eficiente para a diferenciação entre os acessos. No entanto, os autores não obtiveram um dendrograma dos descritores agronômicos semelhante ao produzido pela técnica de RAPD, pois nem sempre é possível encontrar altas correlações entre os descritores agronômicos e RAPD. Isso porque as características morfológicas da semente, apesar de serem importantes ferramentas para análise da diversidade genética em germoplasma, têm parte de seus fenótipos controlados por grupos de vários genes, bem como condicionados pelo fator ambiental. Alguns desses genes encontram-se em regiões mui-

Tabela 1. Descrição das variáveis qualitativas analisadas e sua distribuição nas 33 variedades de arroz da Baixada Maranhense ${ }^{(1)}$

\begin{tabular}{|c|c|c|}
\hline Característica & Classe & Freqüência $(\%)$ \\
\hline \multirow[t]{3}{*}{ Cor das glumelas } & Palha & 69,69 \\
\hline & Dourada & 18,18 \\
\hline & Marron e palha & 12.12 \\
\hline \multirow[t]{3}{*}{ Cor das glumas } & Palha & 87,87 \\
\hline & Dourada & 12,12 \\
\hline & Marron & 12,12 \\
\hline \multirow[t]{3}{*}{ Pubescência } & Ausente & 84,84 \\
\hline & Média & 6,06 \\
\hline & Forte & 9,09 \\
\hline \multirow[t]{6}{*}{ Cor do apículo } & Palha & 36,36 \\
\hline & Pardo & 15,15 \\
\hline & Dourado & 12,12 \\
\hline & Marrom & 12,12 \\
\hline & Preto & 12,12 \\
\hline & Outras & 12,20 \\
\hline \multirow[t]{3}{*}{ Tipo de grão } & Curto & 9,09 \\
\hline & Médio & 36,36 \\
\hline & Longo & 54,54 \\
\hline \multirow[t]{4}{*}{ Forma do grão } & Arredondada & 3,03 \\
\hline & Semi-arredondada & 69,69 \\
\hline & Meio-alongada & 27,27 \\
\hline & Alongada & 30,30 \\
\hline \multirow[t]{8}{*}{ Peso de 1.000 grãos } & $<22,5$ & 21,21 \\
\hline & $22,6-24,0$ & 12,12 \\
\hline & $24,1-25,5$ & 9,09 \\
\hline & $25,6-27,0$ & 15,15 \\
\hline & $27,1-28,5$ & 9,09 \\
\hline & $28,6-30$ & 6,06 \\
\hline & $30,1-31,5$ & 9,09 \\
\hline & 233 & 3.03 \\
\hline \multirow[t]{3}{*}{ Arista } & Aristada & 39,39 \\
\hline & Microaristada & 39,39 \\
\hline & Mútica & 21.21 \\
\hline
\end{tabular}

${ }^{(1)}$ Os dados foram obtidos de $200 \mathrm{~g}$ de sementes; o tipo de grão foi avaliado em 20 grãos; a forma do grão foi determinada pela razão comprimento/largura; o peso de 1.000 grãos foi feito com quatro repetições de 1.000 sementes. 
to pequenas do genoma, difíceis de serem detectadas pela técnica de RAPD que é um marcador molecular de sequiência curta e aleatória.

$\mathrm{Na}$ estimativa da diversidade morfológica, foram consideradas as oito características apresentadas na Tabela 1. A presença ou ausência da característica foi transformada em dados binários, posteriormente agrupados pelo método UPGMA (Figura 1A). Considerando um nível de similaridade de $37 \%$, podemos observar a formação de cinco grupos. O grupo 1, formado por oito variedades, apresenta uma relação comprimento/largura de 3,26. Este grupo apresenta dois subgrupos, e caracteriza-se por apresentar variedades de grãos longos e menor peso de 1.000 grãos. O primeiro subgrupo é formado por grãos não pubescentes e o segundo por grãos pubescentes. As variedades denominadas de Lageado (16) Lageado liso (31) e Lageado sem pêlo (19) apresentam índice de similaridade de $34 \%$, possuem ciclo mais longo e produtividade em torno de $4.000 \mathrm{~kg} / \mathrm{ha}$, segundo Coradin \& Fonseca (1984).

O grupo 2 também está dividido em dois subgrupos: o primeiro corresponde às variedades aristadas e micro-aristadas e o segundo apresenta cinco variedades, com índices de similaridades de $50 \%$, sendo que duas variedades deste grupo, Palha murcha (33) e Arroz 70 (12), são semelhantes em todas as características analisadas. A variedade Bacabinha (29) (grupo 2), por apresentar grão curto, do tipo redondo e cores incomuns, não se agrupou com nenhuma das outras variedades. Este grupo 2 é formado por nove variedades e possui uma relação comprimento/largura do grão de 2,40.

Os grupos 3 e 4 são formados por variedades de grãos médios, arredondados, com arista, e variação nas cores das glumas e glumelas. No grupo 3, formado por nove variedades, destaca-se o agrupamento do Zebu branco (4) com o Canela de ferro (26) que têm a maioria de suas características semelhantes. As denominações Zebu e Zebu branco são comuns em muitas variedades; Fonseca et al. (1982) registraram em uma coleta oito variedades com este nome, entre as tradicionalmente cultivadas no Maranhão.
Neste grupo estão nove variedades e a relação comprimento/largura de grão foi de 2,10. As cinco variedades que formam o grupo 4 apresentam grãos arredondados e de cor mais escura e possuem a relação comprimento/largura do grão de 1,86.

Finalmente, duas variedades, Manteiga (17) e Pingo d'água (20), formaram o quinto grupo, com grãos curtos e médios e glumas escuras (pardas).

Independentemente dos outros fatores, os agrupamentos mostrados na Figura 1A estão organizados por ordem decrescente da relação comprimento/ largura caracterizando as diferentes formas e tamanhos dos grãos. No grupo 1 estão as variedades de grãos mais alongados e no grupo 4 as de grãos mais arredondados.

\section{Marcadores RAPD}

O protocolo utilizado foi eficiente para a extração do DNA das variedades estudadas. Entretanto, por problemas de otimização, as seguintes variedades não foram analisadas pela técnica de RAPD: Agulhinha branco (1), Agulhinha vermelho (2), Maroca (3), Zebu branco (4), Canadá (9), Bacaba roxa (10), Cana roxa (11) e Arroz 70 (12). Para fins de comparação, foram introduzidas na análise as variedades melhoradas IAC 25, IAC 47, IAC 1278, IR 08 e Caiapó, totalizando 30 amostras.

Dos 20 iniciadores OPA01 a OPA20 testados, apenas cinco foram selecionados para o estudo da similaridade entre os genótipos de arroz da região da Baixada Maranhense. O critério utilizado foi a presença de bandas polimórficas que obtivessem uma melhor qualidade e visualização dos produtos de amplificação. Os iniciadores selecionados foram OPA03, OPA04, OPA05, OPA10 e OPA18 que geraram 32 bandas polimórficas e sete monomórficas. Os iniciadores OPA03 e OPA04 foram os que geraram maior número de produto de amplificação, com dez fragmentos cada.

Em cem iniciadores testados, Mailer et al. (1994) selecionaram apenas seis para análise de divergência genética entre 23 cultivares de Brassica napus. Gustine et al. (2002) analisaram a diversidade genética de nove populações de trevo-branco com apenas 


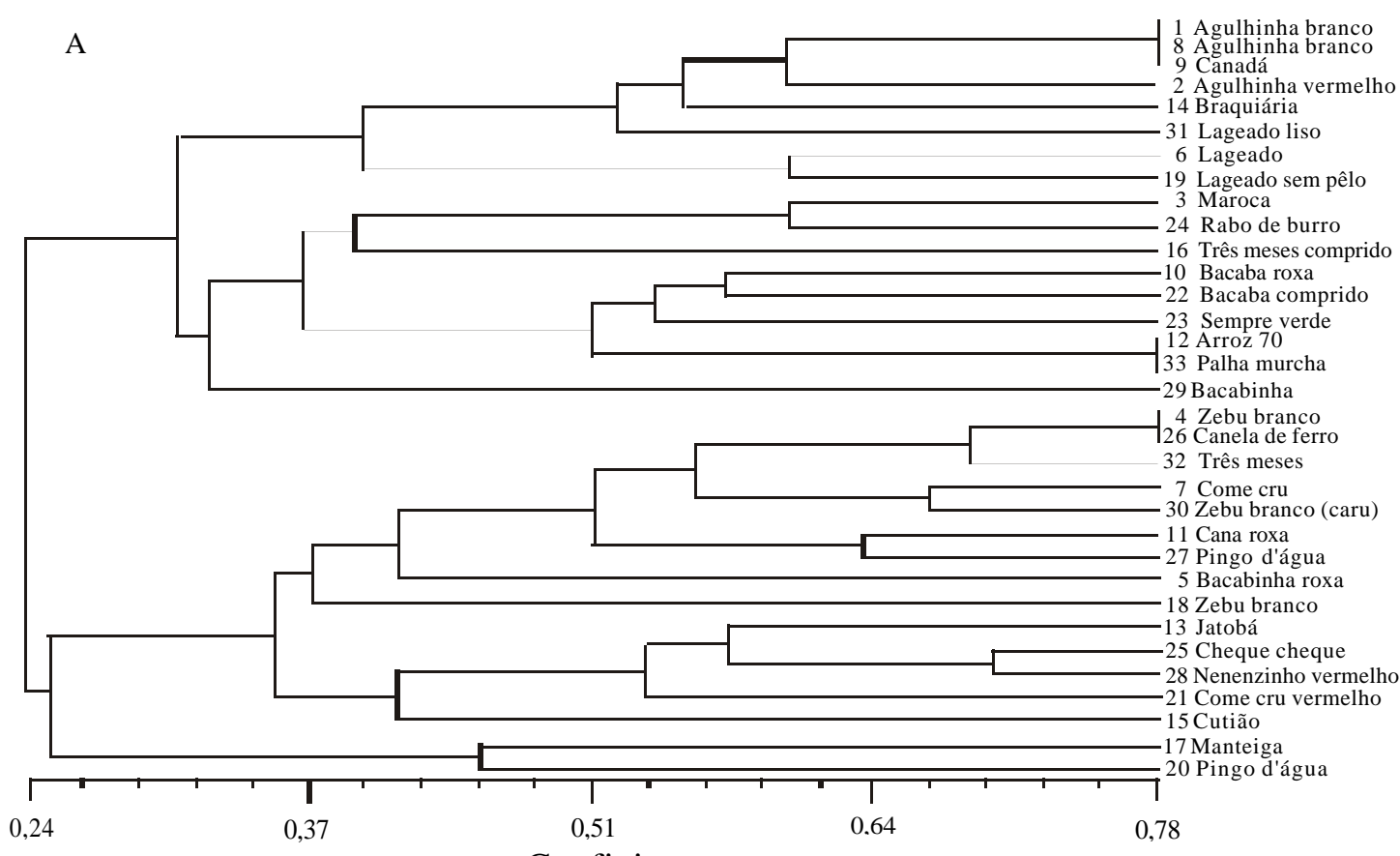

Coeficiente

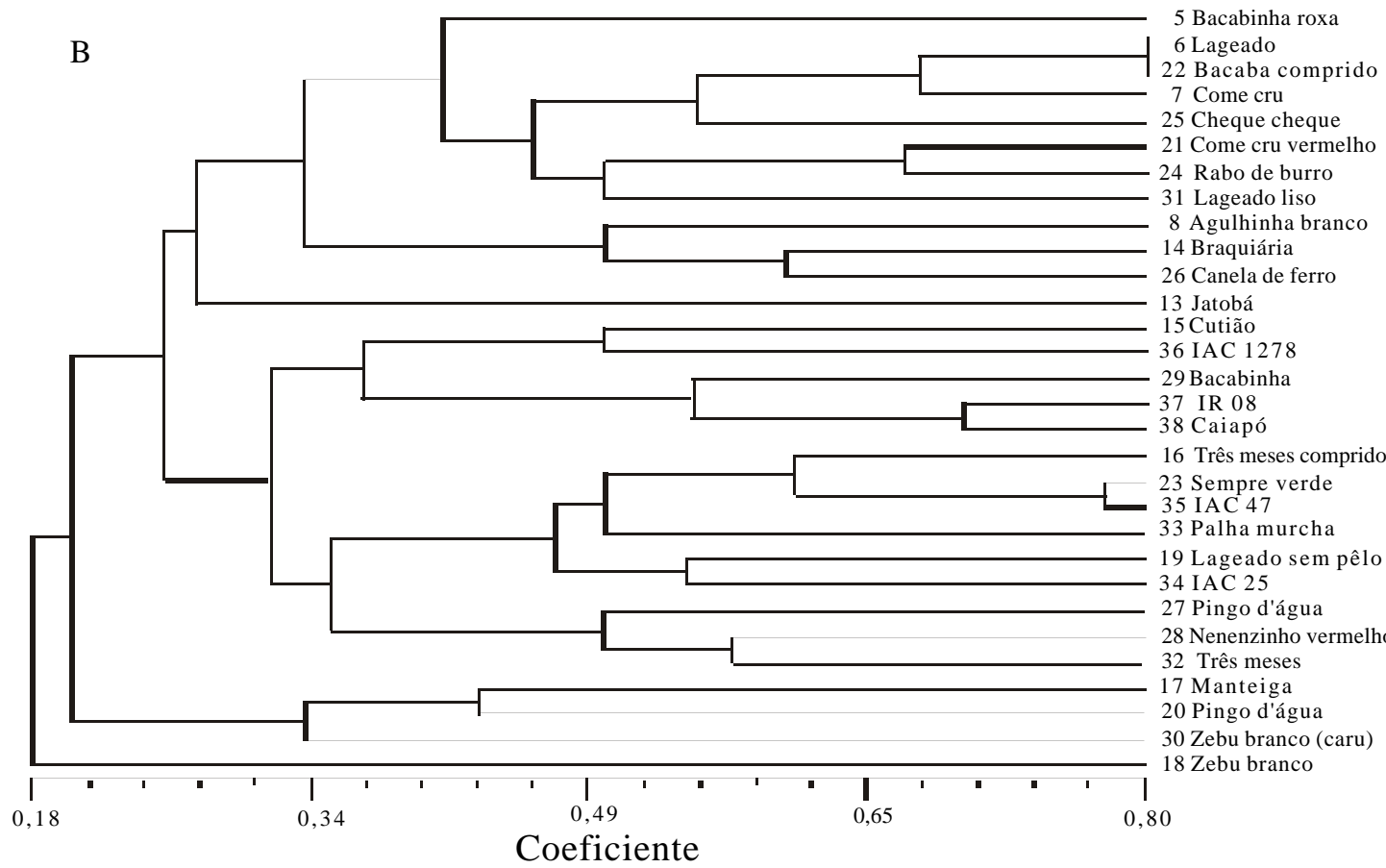

Figura 1. Dendrograma de similiaridade genética obtido a partir das análises morfológicas de 33 variedades de arroz (A) e dendrograma de similaridade genética obtido a partir dos produtos de amplificação do DNA por RAPD de 33 variedades de arroz (B). 
três iniciadores - OPA 08, OPH 12, OPH 14 - num total de 28 fragmentos polimórficos. Os fragmentos gerados apresentaram tamanhos de 300 a 2.500 pb. Foram avaliadas bandas mais fortes ou médias, uma vez que, segundo Weeden et al. (1992), bandas fracas podem gerar erros de $2 \%$ a $7 \%$, sugerindo o uso de repetições nas análises e interpretação apenas das bandas intensas. Outros pesquisadores têm usado repetição parcial ou completa das amostras e a eliminação das bandas que não são consistentemente reproduzíveis (Yang \& Queiroz, 1993; Novy et al., 1994).

O dendrograma construído considerando-se valores de similaridade calculados com base nos dados de RAPD está apresentado na Figura 1B. No dendrograma, se considerarmos um índice de similaridade de $30 \%$, podemos verificar que a árvore encontra-se dividida em quatro grupos.

O grupo 1 possui três ramificações, quando consideramos um índice de similaridade de $50 \%$, porém a forma de agrupamento não coincide com aquela definida com base em caracteres morfológicos, indicando, que as variedades foram agrupadas por outras características que não a de subespécie indicae japonica como se esperava. Por sua vez, Zeng et al. (2001) conseguiram separar as variedades de arroz utilizando marcadores.

O grupo 2 é constituído de cinco variedades, com três variedades melhoradas, indicando similaridade ou a existência de um progenitor comum entre elas. Também no grupo 3, foram agrupadas duas variedades melhoradas, perfazendo um total de nove. Neste grupo, encontram-se duas variedades de nomes semelhantes: Três meses (32) e Três meses comprido (16). A variedade Sempre verde (23) apresentou uma similaridade acima de $70 \%$ com a IAC 47 melhorada (Figura 1B).

\section{Teores de proteína bruta nos grãos}

As 33 variedades de arroz foram divididas em três grupos de acordo com o seu teor de proteína bruta (PB): Grupo A, 6-7\% de PB (baixo); Grupo B, 7-8\% de PB (intermediário) e Grupo C, mais de $8 \%$ de PB (elevado) (Tabela 2). Entre as variedades avaliadas, destacou-se a variedade Manteiga (17), com maior acúmulo de PB (10,48\%) e classificada como de grão curto e meio alongado.

De modo geral, as variedades com maiores teores de PB apresentaram os grãos arredondados (menor relação comprimento/largura), independentemente do comprimento do grão. Existe uma relação negativa $(r=-0,82)$ entre os teores de PB e a relação comprimento/largura para as variedades com maior e menor PB (Figura 2). Esta regra, entretanto, não é absoluta, existindo variedades com alto teor de PB, como Braquiária $(14)(8,85)$, com alta relação comprimento/largura $(3,10)$, e ao contrário, variedades com baixos teores de PB como o Cutião (15) $(6,80)$, com baixa relação comprimento/largura $(1,99)$.

Tabela 2. Teores de proteína bruta e relação comprimento/largura em grãos de arroz de variedades de sequeiro coletadas na Baixada Maranhense e sua classificação em grupos A, B e C de acordo com o teor de proteína bruta.

\begin{tabular}{|c|c|c|c|}
\hline Grupo & Variedade & $\begin{array}{l}\text { Proteína } \\
\text { bruta (\%) }\end{array}$ & $\begin{array}{c}\text { Relação } \\
\text { comprimento/ } \\
\text { largura }\end{array}$ \\
\hline \multirow[t]{9}{*}{ A (PB 6-7\%) } & Agulhinha vermelho (2) & 6,94 & 3,29 \\
\hline & Agulhinha branco (8) & 6,63 & 3,30 \\
\hline & Cutião (15) & 6,80 & 1,99 \\
\hline & Três meses comprido (16) & 6,88 & 2,56 \\
\hline & Lajeado sem pêlo (19) & 6,22 & 3,28 \\
\hline & Pingo d'água (20) & 6,96 & 2,36 \\
\hline & Rabo de burro (24) & 6,98 & 2,40 \\
\hline & Canela de ferro (26) & 6,60 & 2,70 \\
\hline & Palha murcha (33) & 6,46 & 2,28 \\
\hline \multirow[t]{14}{*}{ B (PB 7-8\%) } & Agulhinha branco (1) & 7,69 & 3,35 \\
\hline & Zebu branco (4) & 7,49 & 1,88 \\
\hline & Bacabinha roxa (5) & 7,85 & 1,77 \\
\hline & Lajeado (6) & 7,27 & 3,16 \\
\hline & Come cru (7) & 7,65 & 1,90 \\
\hline & Come cru vermelho (21) & 7,47 & 1,92 \\
\hline & Bacaba comprido (22) & 7,59 & 2,47 \\
\hline & Sempre verde (Viana) (23) & 7,38 & 3,28 \\
\hline & Cheque cheque (25) & 7,49 & 1,72 \\
\hline & Pingo d'água (27) & 7,00 & 1,75 \\
\hline & Bacabinha (29) & 7,97 & 1,50 \\
\hline & Zebu branco (caru) (30) & 7,61 & 1,80 \\
\hline & Lajeado liso (31) & 7,31 & 3,30 \\
\hline & Sempre verde (32) & 796 & 1.95 \\
\hline \multirow[t]{10}{*}{$\mathrm{C}(\mathrm{PB}>8 \%)$} & Maroca (3) & 8,40 & 2,48 \\
\hline & Canadá (9) & 8,34 & 3,30 \\
\hline & Bacaba roxa (10) & 9,05 & 2,14 \\
\hline & Cana roxa (11) & 9,46 & 1,82 \\
\hline & Arroz 70 (12) & 8,49 & 2,50 \\
\hline & Jatobá (13) & 8,45 & 1,74 \\
\hline & Braquiária (14) & 8,85 & 3,10 \\
\hline & Manteiga (17) & 10,48 & 1,63 \\
\hline & Zebu branco (18) & 8,02 & 1,84 \\
\hline & Nenenzinho vermelho (28) & 8,25 & 1,70 \\
\hline
\end{tabular}




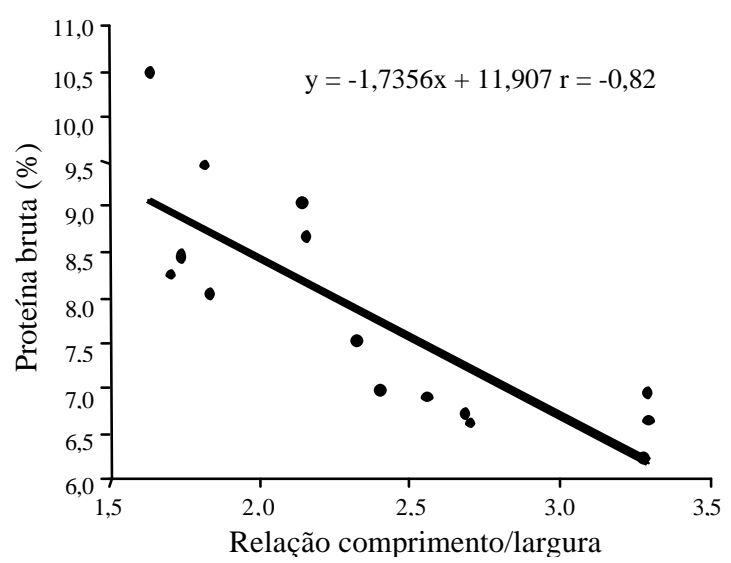

Figura 2. Relação entre o teor de proteína bruta dos grãos e a relação comprimento/largura para as seis variedades que apresentaram menor e para as seis com maior teor de proteína bruta nos grãos.

O agrupamento das variedades pelo teor de proteína bruta (Tabela 2) não coincide com os grupos obtidos no dendrograma da análise morfológica (Figura 1A). As variedades com elevados teores de PB distribuem-se por todos os grupos, sendo que Manteiga (17) e Pingo d'água (27), que formaram um grupo separado apresentaram PB de 10,48\% e 7,00\%, respectivamente. Resultados semelhantes são observados no dendrograma obtido com o RAPD, embora algumas variedades tenham sido retiradas deste último (Figura 1B).

Ferraz Junior et al. (2001) usaram variedades com o mesmo nome, mas que apresentaram elevados teores de PB: Zebu branco (18) (12,60\%), Pingo d'água (27) (10,48\%), Canela de ferro (26) $(9,09 \%)$ e Palha murcha (33) $(8,69 \%)$, ao contrário dos obtidos no presente trabalho; constataram que algumas variedades apresentaram teores diferentes de PB quando cultivadas no Rio de Janeiro ou no Maranhão, enquanto em outras variedades, os teores de PB mantiveram-se constantes.

Se as variedades Pingo d'água (20) e Zebu branco (18) fossem as mesmas estudadas por Ferraz Junior et al. (2001), elas formariam com a variedade Manteiga (17) um agrupamento com altos teores de PB $(10,48 \% ; 12,6 \%$ e $10,48 \%$, respectivamente), constituindo o grupo 4 no dendrograma de RAPD (Figura 1B). Neste caso, existem duas possibilidades: variedades diferentes possuem o mesmo nome, ou as mesmas variedades, submetidas a diferentes condições ambientais, particularmente as que conduzem ao acúmulo de $\mathrm{N}$-amino livre (Ferraz Junior et al., 2001), modificam os teores de PB desse grupo. Nesse sentido, é interessante observar que as sementes usadas por Ferraz Junior et al. (2001) foram originárias de diferentes zonas fisiográficas do Maranhão, ao passo que as variedades deste experimento foram coletadas na região da Baixada Maranhense.

\section{Conclusões}

1. Os descritores morfológicos e moleculares separam as variedades em grupos que não coincidem inteiramente.

2. Os maiores acúmulos de proteína bruta ocorrem em variedades que apresentam as menores relações comprimento/largura do grão.

\section{Agradecimento}

Ao CNPq e à Faperj, pelo suporte financeiro; a Mariam Lis M. Stark, pela criteriosa revisão do manuscrito.

\section{Referências}

CORADIN, L.; FONSECA, J. R. Coleta de germoplasma de arroz no Estado do Maranhão. Brasília: Embrapa-Cenargen, 1984. 19 p. (Documentos, 2).

DAHLBERG, J. A.; ZHANG, X.; HART, G. E.; MULLET J. E. Comparative assessment of variation sorghum germplasm accessions using seed morphology and RAPD measurements. Crop Science, Madison, v. 42, n. 1, p. 291-296, 2002.

FERRAZ JUNIOR, A. S. L.; SOUZA, S. R.; STARK, E. M. L. M.; FERNANDES, M. S. Crude protein in rice grown in different environmental conditions. Physiology and Molecular Biology of Plants, New Delhi, v. 7, n. 2, p. 149-157, 2001.

FERREIRA, M. E.; GRATTAPAGLIA, D. Introdução ao uso de marcadores moleculares em análise genética. 3. ed. Brasília: Embrapa-Cenargen, 1998. 220 p.

FONSECA, J. R.; SILVA, T. H. Identificação de duplicidades de acessos de feijão por meio de técnicas multivariadas. Pesquisa Agropecuária Brasileira, Brasília, v. 34, n. 3, p. 409414, mar. 1999.

FONSECA, J. R.; RANGEL, P. H. N.; BEDENDO, I. P.; SILVEIRA, P. M. da; GUIMARÃES, E. P.; CORADIN,L. 
Características botânicas e agronômicas de cultivares e raças regionais de arroz (Oryza sativa L.) coletadas no Estado do Maranhão. Goiânia: Embrapa-CNPAF/ Embrapa-Cenargen, 1982. 42 p. (Embrapa-CNPAF. Boletim de Pesquisa, 1).

GLASS, A. D. M.; SIDDIQI, M. X.; GILES, K. I. Correlation's between potassium uptake and hydrogen efflux in barley varieties. Plant Physiology, Rockville, v. 68 , p. $458-459,1981$

GOSTIMSKY, A. S.; KOKAEVA, Z. G.; BOBROVA, V. K Use of molecular marker for the analysis of plant genome. Research Journal of Genetics, Moscow, v. 11, n. 35, p. $1538-1549,1999$.

GUSTINE, D. L.; VOIGT, P. W.; BRUMMER, C. E.; PAPADOPOULOS, Y. A. Genetic variation of RAPD markers for North American white clover collection and cultivars. Crop Science, Madison, v. 42, p. 343-347, 2002.

JACCARD, P. Étude comparative de la distribution florale dans une portion des Alpes et des Jura. Société Vaudoise des Sciences Naturelles Bulletin, Lausanne, v. 3, n. 7, p. 547-579, 1976.

JULIANO, B. O. Polysaccharides, proteins and lipids of rice. In: JULIANO, B. O. (Ed.). Rice: chemistry and technology. $2^{\text {nd }}$ ed. St. Paul: American Association of Cereal Chemists, 1985. p. 59-175.

MAILER, R. J.; CARTH, R.; FRISTENSKY, B. Discrimination among cultivars of rapeseed (Brassica napus L.) using DNA polymorphisms amplified from arbitrary primers. Theoretical and Applied Genetics, Berlin, v. 87, n. 6, p. 697-704, 1994.

MOLINO, M. M. Relationship between wheat grain protein percentage and grain yield, plant growth and mutation at anthesis. Journal of Plant Nutrition, New York, v. 15, n. 2, p. 169-178, 1992.

NOVY, R. C.; KOBAK, C.; GOFFREDA, J.; VORSA, N. RAPDs identify varietal misclassification and regional divergence in cranberry (Vaccinium macrocarpon Ait.) Pursh. Theoretical and Applied Genetics, Berlin, v. 88, p. 1004-1010, 1994.

RANGEL, N. H. P.; CRUZ, D. C.; VENCOVSKY R.; FERREIRA, P. R. Selection of local lowland rice cultivars based on multivariate genetic divergence. Revista Brasileira de Genética, Ribeirão Preto, v. 14, n. 2, p. 437 453, 1991.

ROHLF, F. J. NTSYS-pc: numerical taxonomy and multivariate analysis system. New York: Exeter Software, 2000. $236 \mathrm{p}$.
SAMBROOK, J.; FRITSCH, E. F.; MANIATIS, T. Molecular cloning: laboratory manual. $2^{\text {nd }}$ ed. New York: Cold Spring Harbor Laboratory Press, 1989. 123 p.

SILVA, A. T. Estudo da divergência genética em acessos de arroz através de marcadores morfológicos e moleculares (RAPD). Lavras: Ufla, 1999. 185 p.

SING, A. K.; SINGH, S. B.; SINGH, S. M. Genetic divergence in scented and fine genotypes of rice (Oryza sativa $\mathrm{L}$.). Journal of Agricultural Research, Washington, v. 17, n. 2, p. 163-166, 1996.

SOUZA, S. R.; STARK, E. M. L.; FERNANDES, M. L. Effects of supplemental-N on the quality of rice proteins. Journal of Plant Nutrition, New York, v. 9, p. 40-49, 1993.

TEDESCO, J. M.; GIANELLO, C.; BOHNEN, H.; VOLKWEISS, S. J. Análise de solos, plantas e outros materiais. Porto Alegre: UFRGS, 1998. 174 p.

TEIXEIRA, S. M.; ROBSON, D.; ALBUQUERQUE, J. M. Agricultura de subsistência na produção de arroz: experiência no Maranhão. Goiânia: Embrapa-CNPAF, 1991. $36 \mathrm{p}$.

THOMAS, M. R.; MATSUMOTO, S.; CAIN, P.; SCOTT, N. S. Repetitive DNA of grapevine: class present and sequences suitable for cultivar identification. Theoretical and Applied Genetics, Berlin, v. 86, p. 173180, 1993.

UNIVERSIDADE ESTADUAL DO MARANHÃO. Núcleo Estadual de Meteorologia e Recursos Hídricos. Mapas climáticos. Disponível em: <http.://www.nemrh.uema.br/meteoro/meteoro.htm>. Acesso em: 8 ago. 1999.

WEEDEN, N. F.; MUEHLBAUER, F. J.; LADIZINSKY, G. Extensive conservation of linkage relationship between pea and lentil genetic maps. Journal of Heredity, Baltimore, v. 83, n. 1, p. 123-129, 1992.

WILLIAMS, J. G. K.; KUBELICK, A. R.; LIVAK, K. J.; RAFALSKI, J. A.; TINGEY, S. V. DNA polymorphisms amplified by arbitrary primers are useful a genetic marker. Nucleic Acids Research, Oxford, v. 18, p. 6531-6535, 1990.

YANG, X.; QUEIROZ, C. Identification and classification of celery cultivars with RAPD markers. Theoretical and Applied Genetics, Berlin, v. 86, p. 205-212, 1993.

ZENG, Y.; LI, Z.; YANG, Z.; WANG, X.; SHEN, S.; ZHANG, H. Ecological and genetic diversity of rice germplasm in Yunnan, China. Plant Genetic Resources Newsletter, Rome, v. 125, p. 24-28, 2001. 